\title{
الطاقة الاستيعابية للنفقات التشغيلية \\ ومرونة الكلفة المالية للسياسة النية النقدية
}

الخبير الدكتور مظهر محمد صالح قاسم البمائ

نائب محافظ البنك المركزي

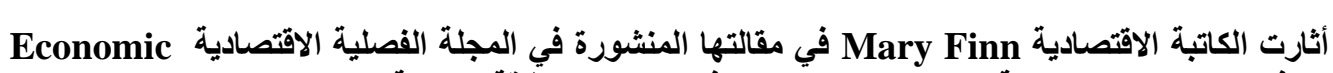

توطئة:

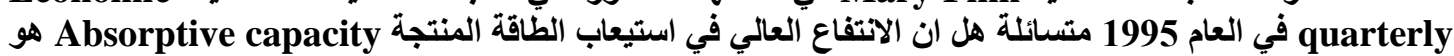

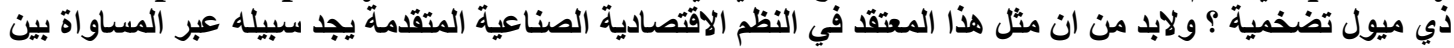

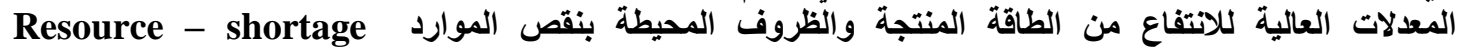
conditions

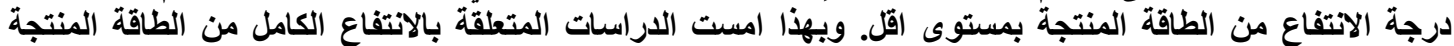
وعلاقتها بالتضخم مرتبطة بالتقلبات الحاصلة في الناتج المحلي الاجمالي والتضخم التفات التفنه.

\section{The Absorptive Capacity of Operational Budget and Monetary Policy Fiscal Cost}

\section{Summery:}

In light of the enquiry raised by the Economist Mary Finn in 1995 concluding that high utilization in absorptive capacity of the economy is of inflationary tendency for industrial countries due to the equality between high rates of utilization of absorptive capacity and resource - shortage conditions leading to price inflation, the same idea was used to prove that budget utilization of operational costs and elevating absorptive capacity at the expense of investment budget leads to inflationary tendency that becomes a burden on financing the step- in policy of the Central bank to control prices through its foreign currency reserves at a time when the economy turned into an importer of non- tradable goods and being subject to Balassa-Samuelson effect based on intensifying non- traded goods price increase in industrial countries in coordination with its growth acceleration to be exported to Iraq as an inflationary force increasing the level of economic imbalances depleting the foreign currency needs of the Central Bank through the increase in the cost of financial or monetary step -in policy which is considered a disease of high consumption societies living on rental resources receiving as a result, price shocks from industrial countries due to the transition towards importing nontradable goods to become tradable goods. 


\section{الطاقة الاستيعابية للنفقات التشغيلية}

\section{ومرونة الكلفة المالية للسياسة النقدية}

ومن المفارقة الفكرية، فقد استخدمنا فكرة الباحثة Mary Finn في مقالتها في اعلاه ولكن بأتجاه

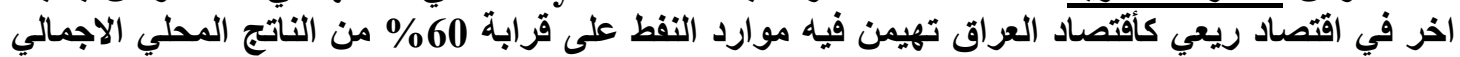

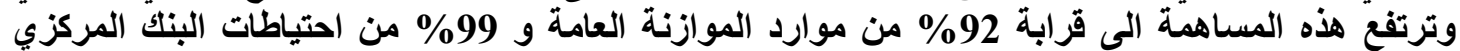

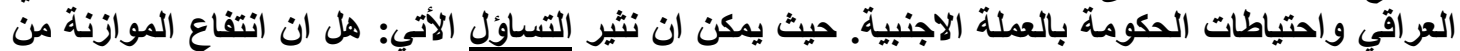

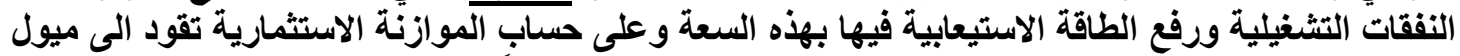

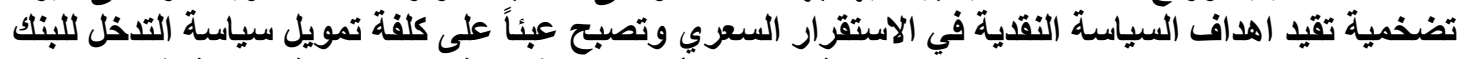

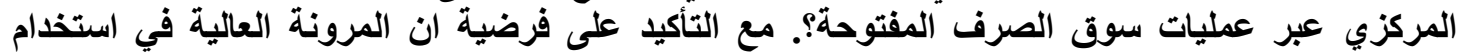

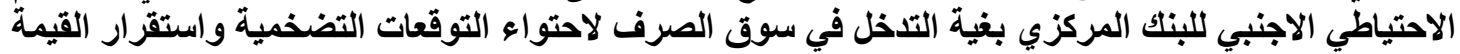

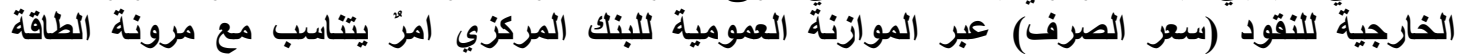

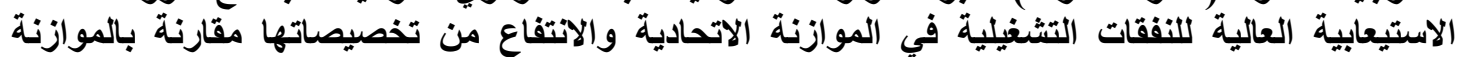

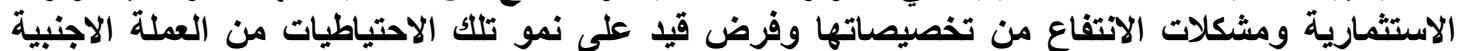

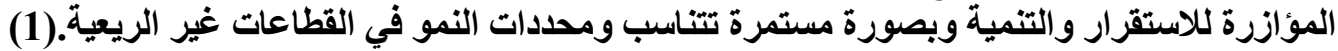

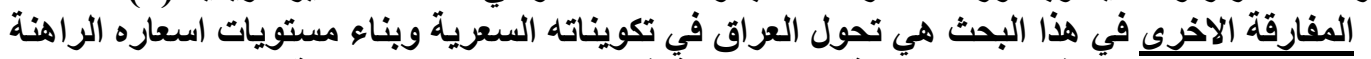

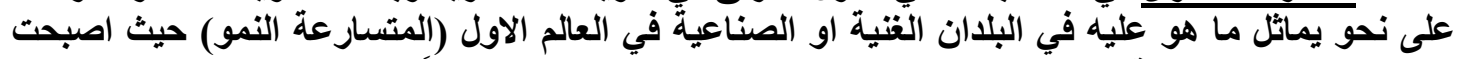

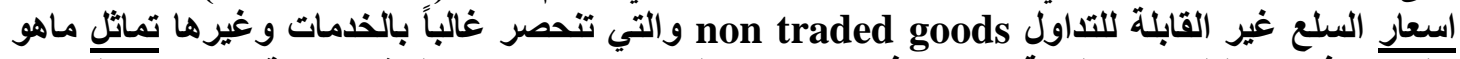

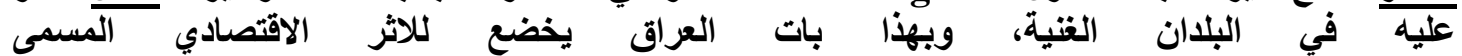
Balassa-Samuelson effect

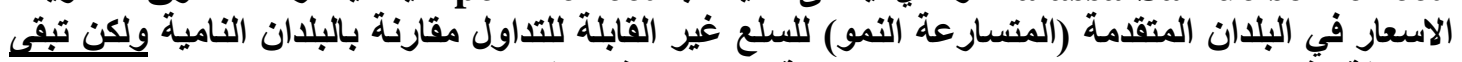

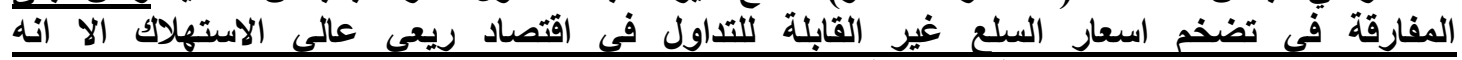

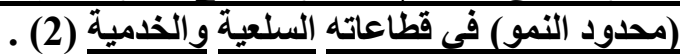

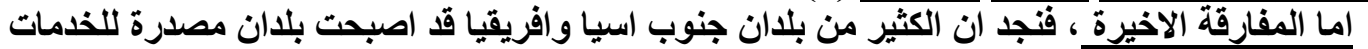

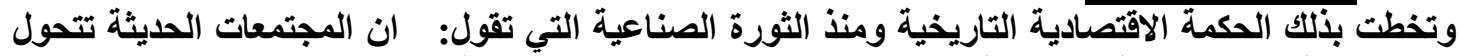

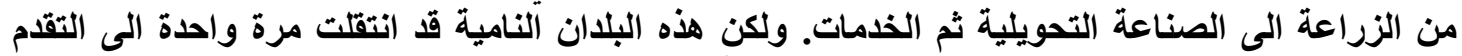

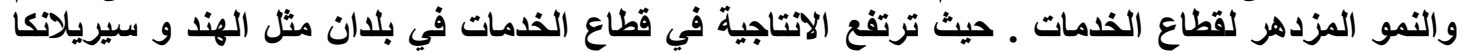

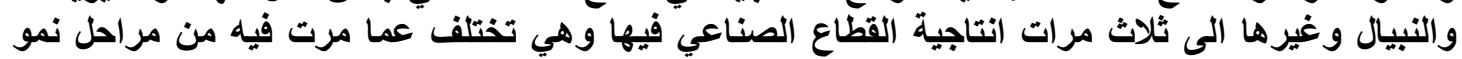

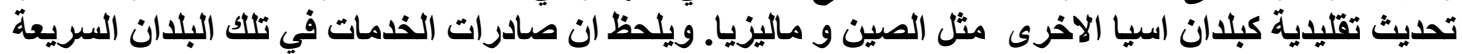

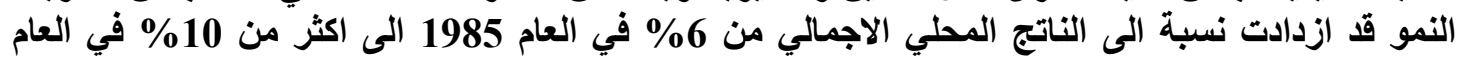

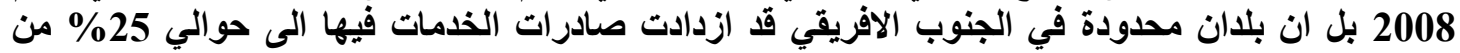




\section{الطاقة الاستبعابية للنفقات النشغيلية}

\section{ومرونة الكلقة المالية للسياسة النقدية}

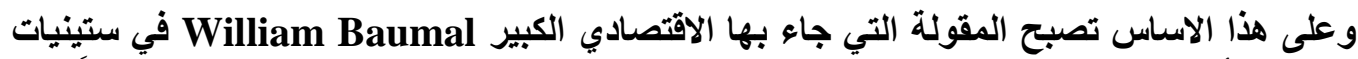

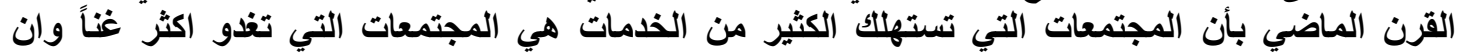

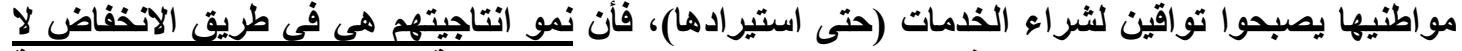

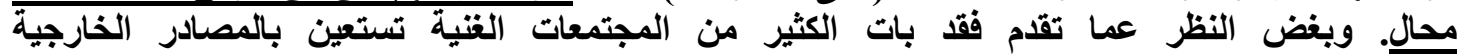

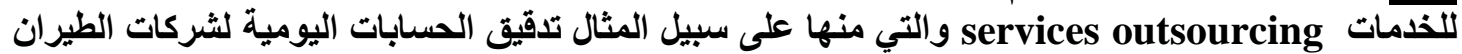

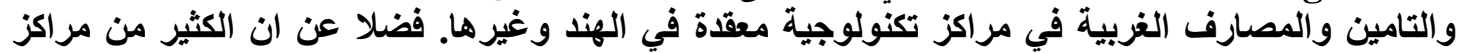

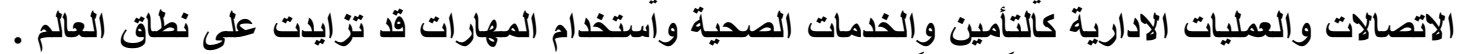

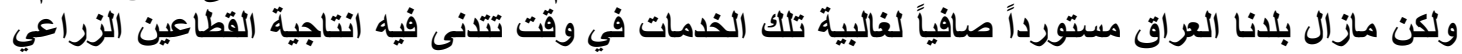

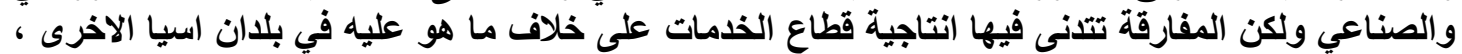

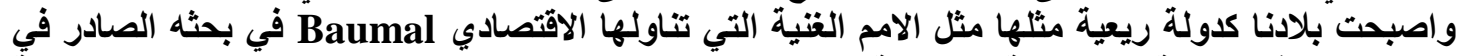

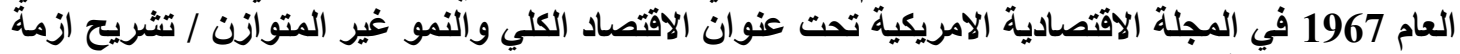

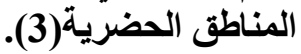

وبهذا امست الخدمات والمهارات والمتطلبات الخدمية من سلع غير قابلة للتداول كما يطلق عليها

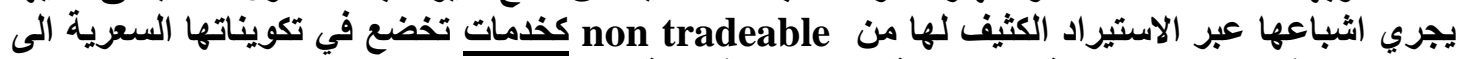
ماهو عليه في البلدان المتقدمة المتسارعة النمو عبر فرضية السعر الواحد

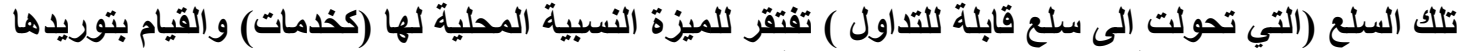

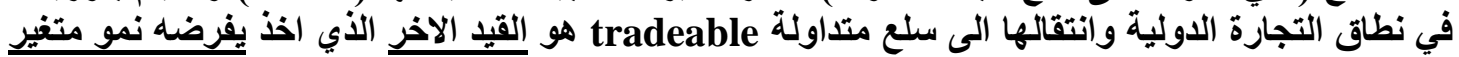

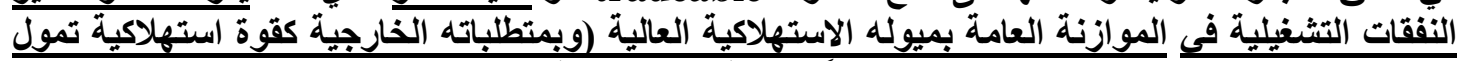

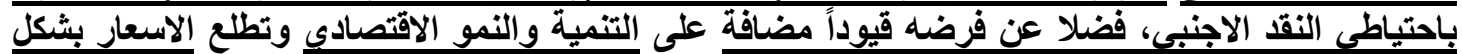

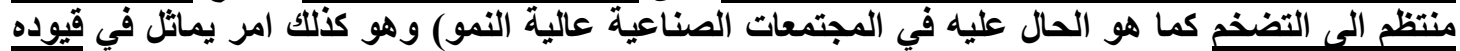

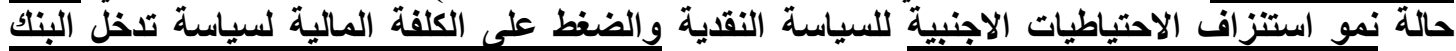

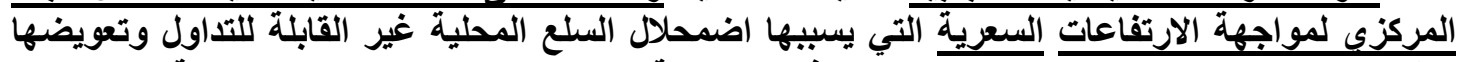

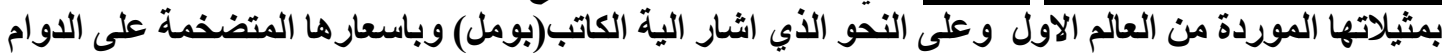

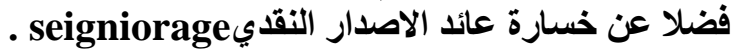


الطاقة الاستبعابية للنفقات التشغيلبة

ومرونة الكافة المالية للسياسة النقدية

1- النفقات التثغيلية والنمو الاقتصادي الكلي :

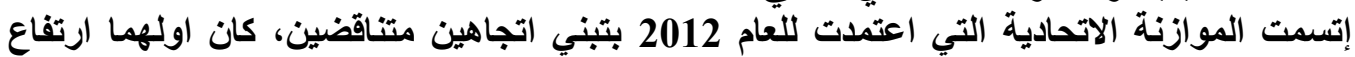

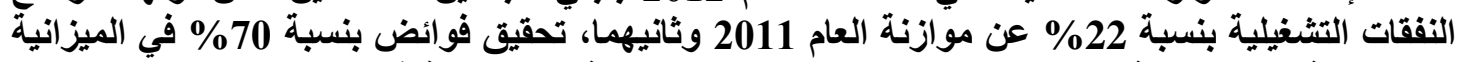

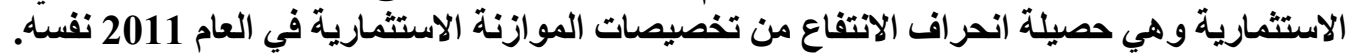

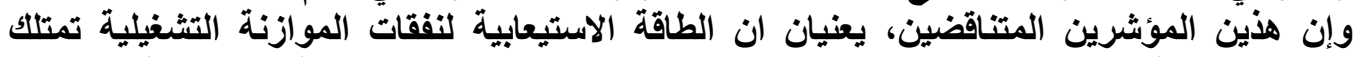

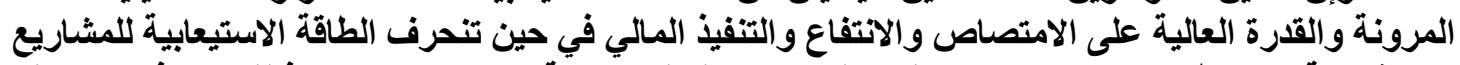

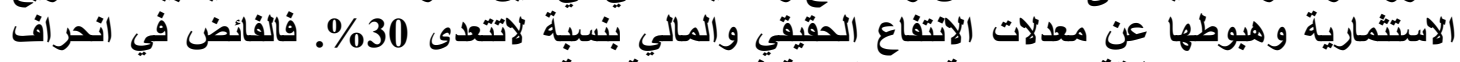

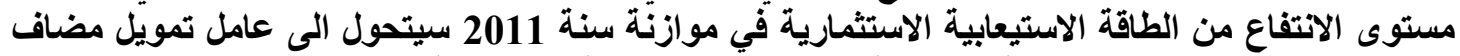

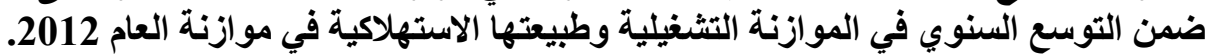

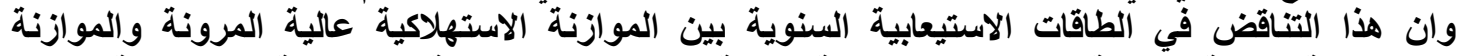

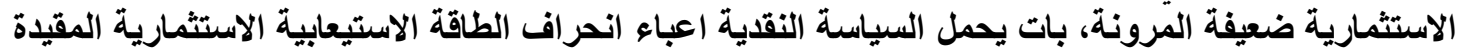

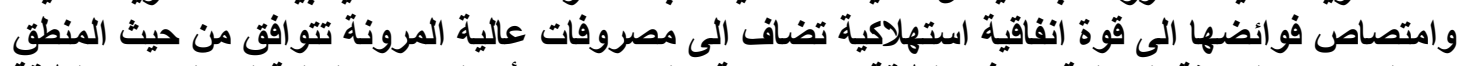

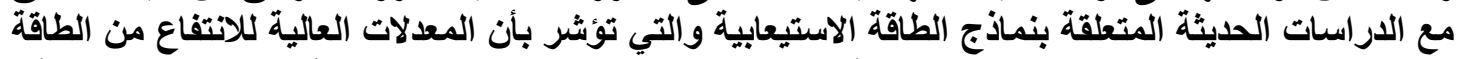
Capacity Utilization

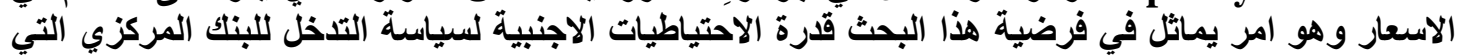

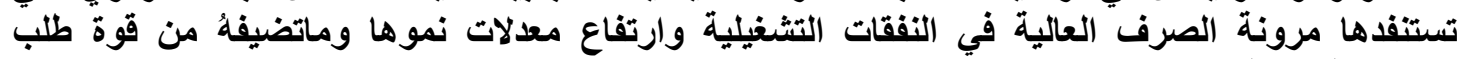

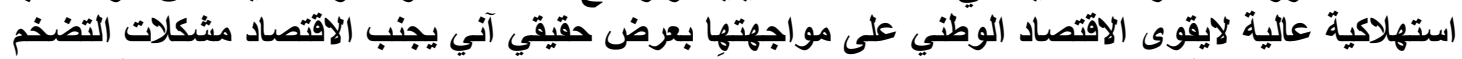

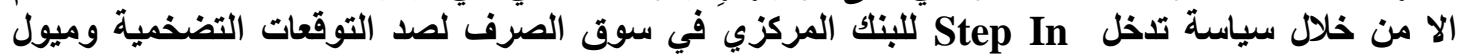

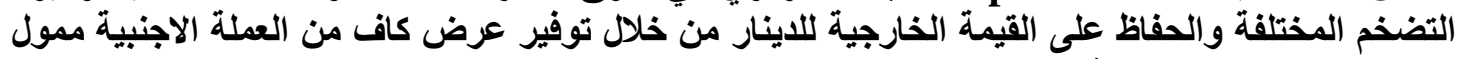

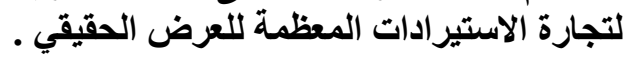

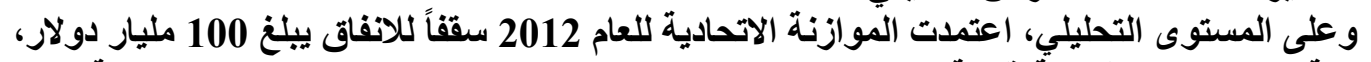

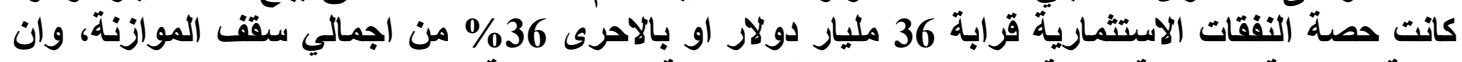

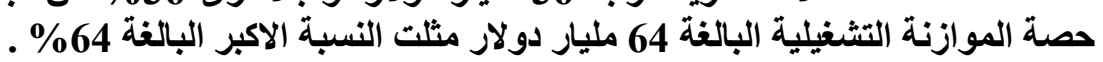

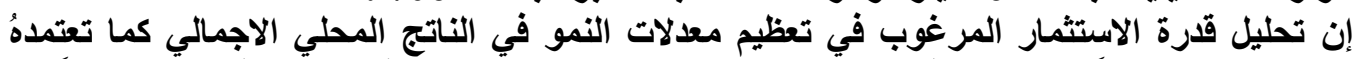

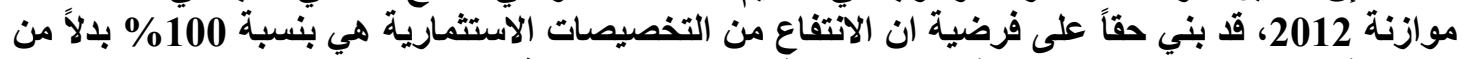

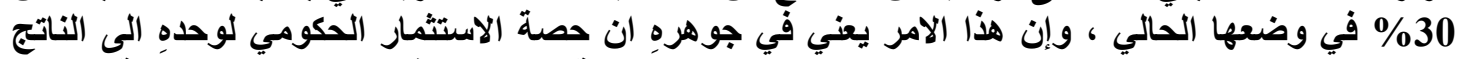

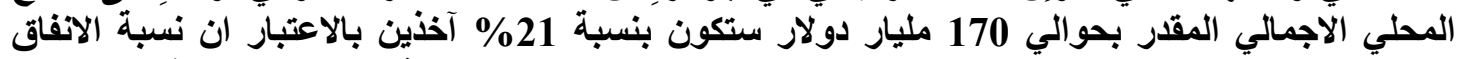

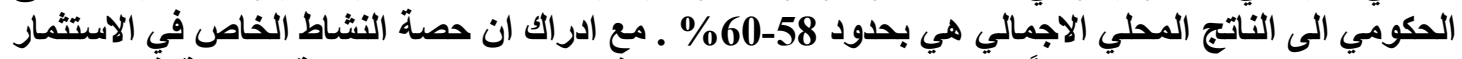

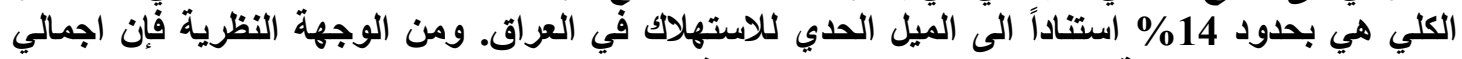

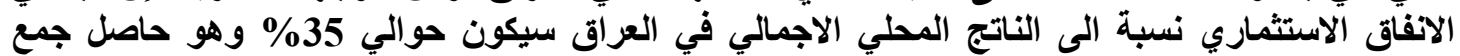

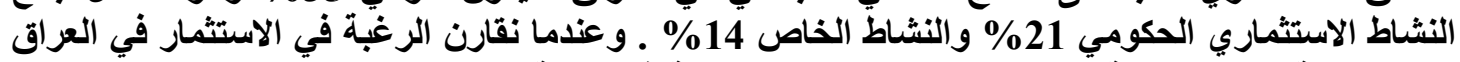

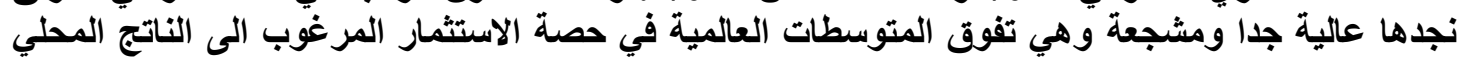

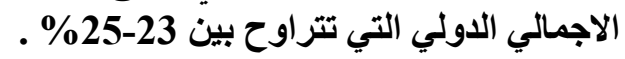




\section{الطاقة الاستيعابية للنفقات التشغغيلية}

\section{ومرونة الكلهة المالية للسياسة النقدية}

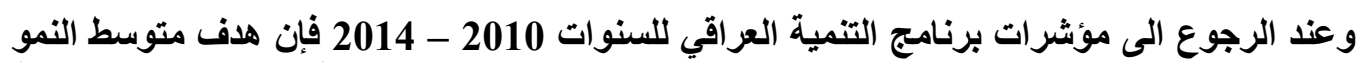

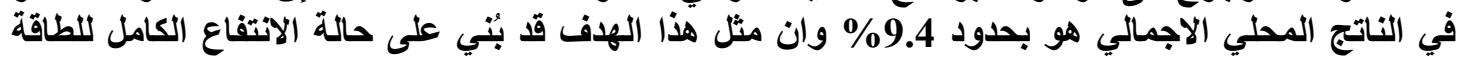

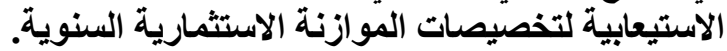

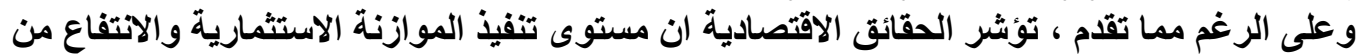

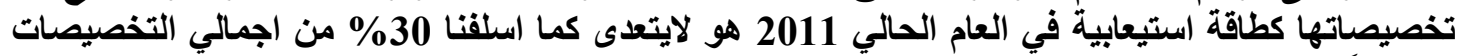

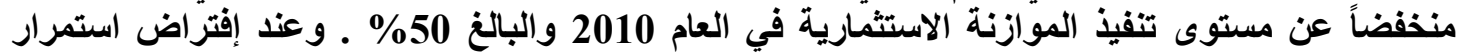

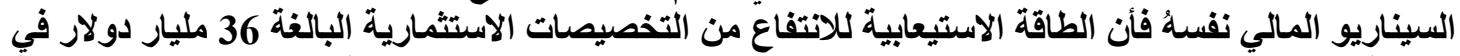

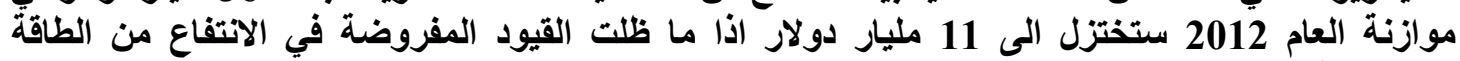
الاستيعابية للاستثمار على حالها.

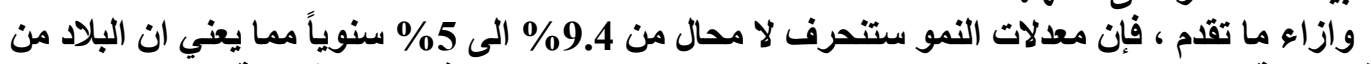

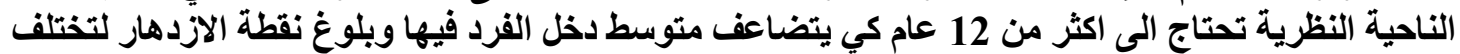

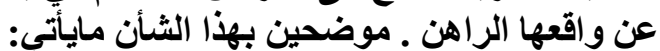

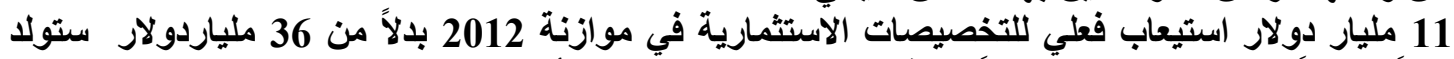

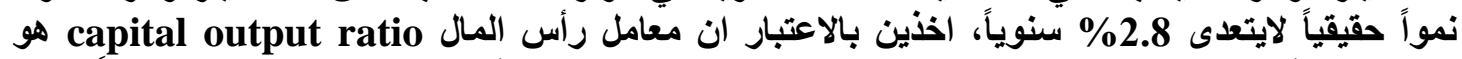

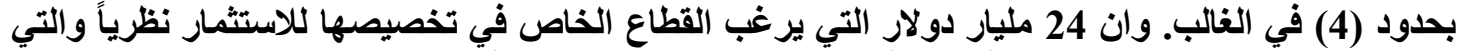

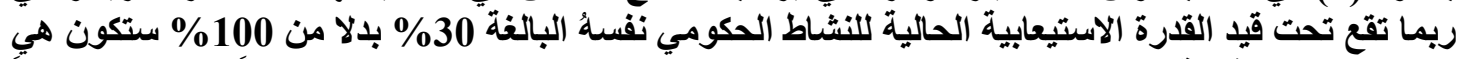

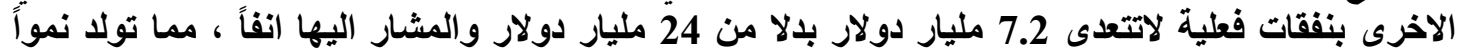

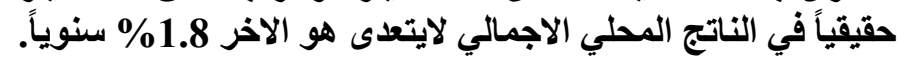

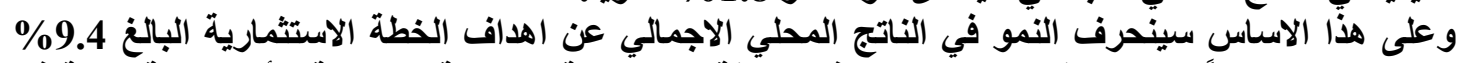

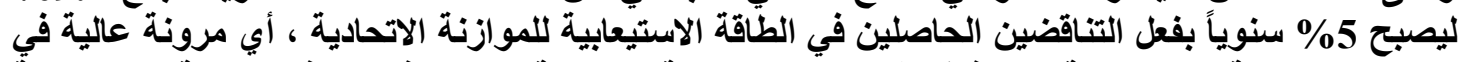

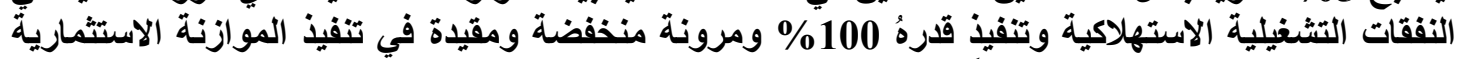

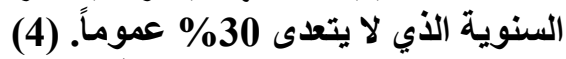

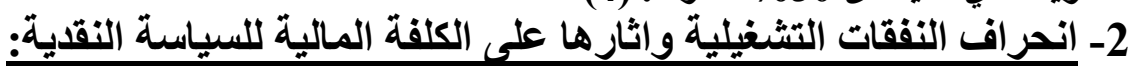

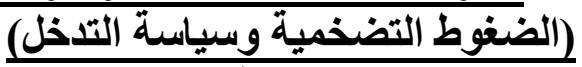

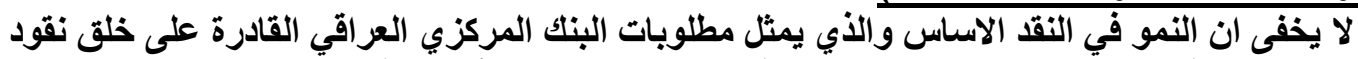

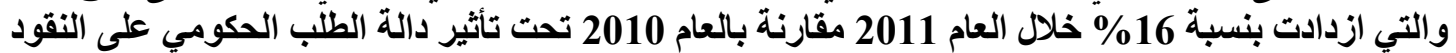

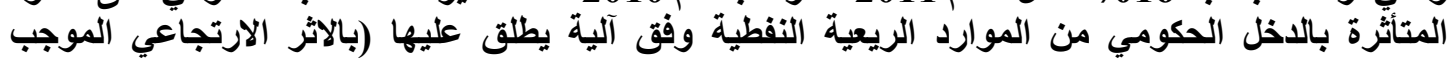
(positive feedback

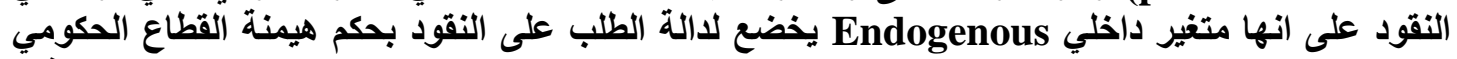

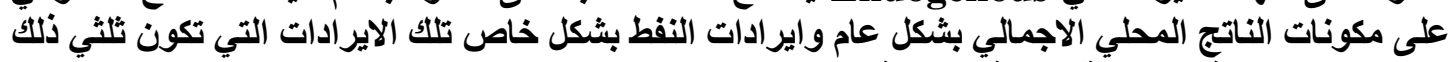

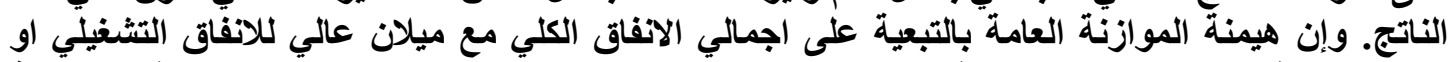

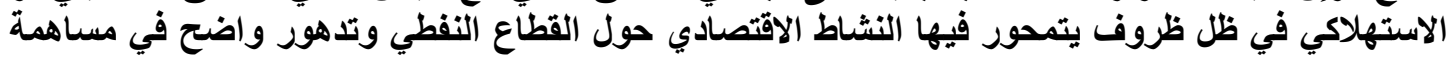

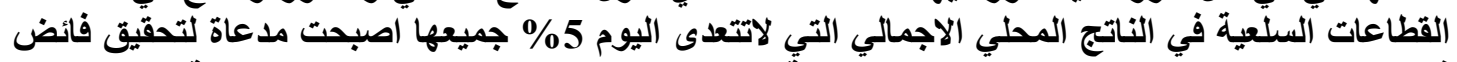

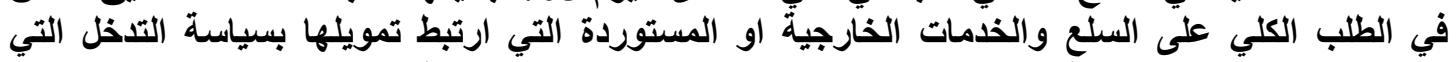

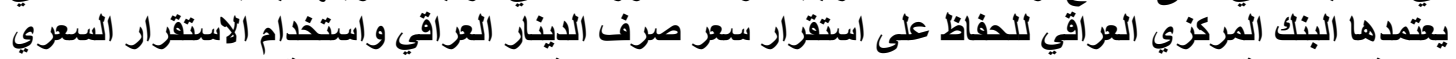

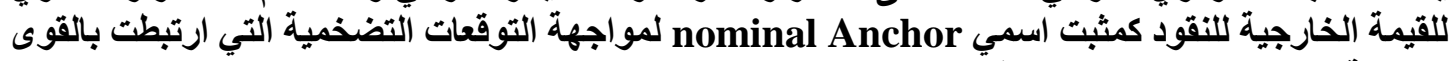

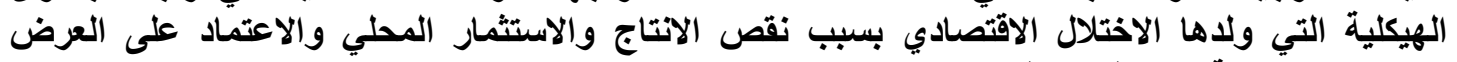
الخارجي لمواجهة ضغوطات الطلب. 
وما لم يتلخل البنتك المركزي يومياً في سوق الصرف بأعتبارهِ سوقاً مركزية فإن انحرافات شديدة

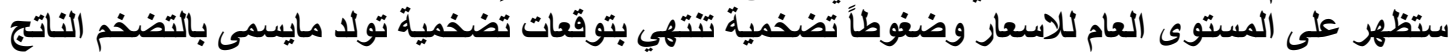

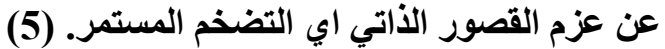

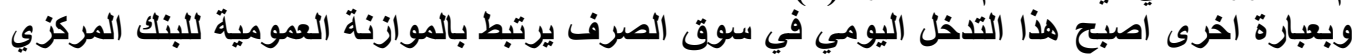

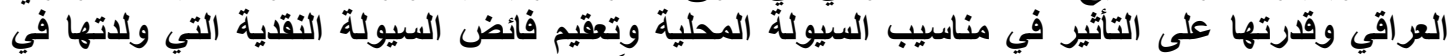

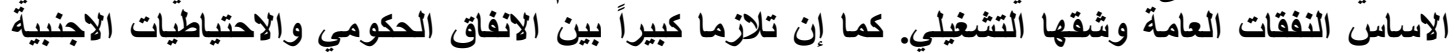

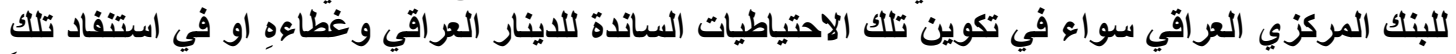

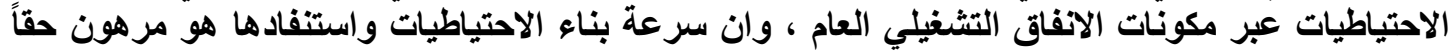

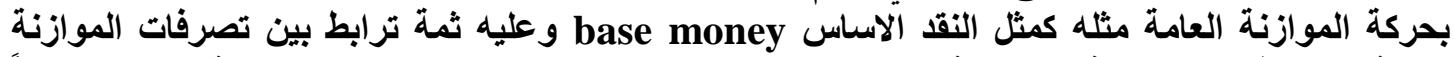

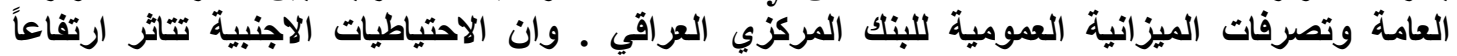

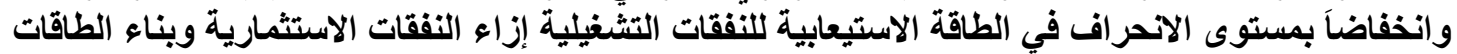

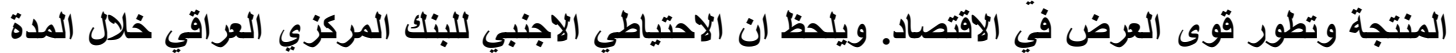

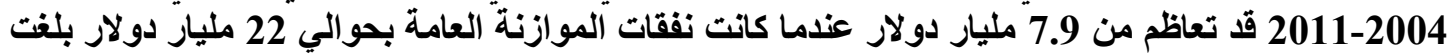

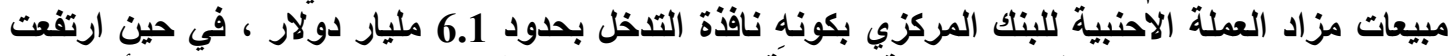

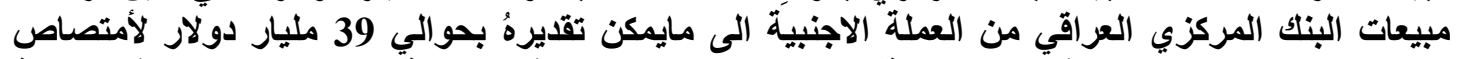

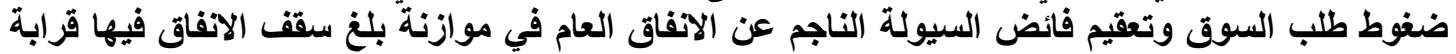

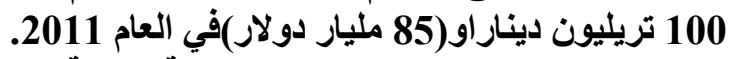

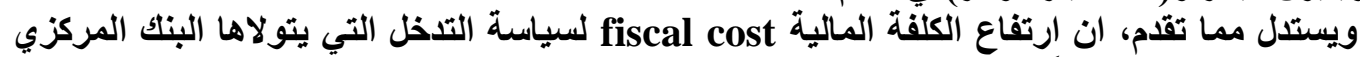

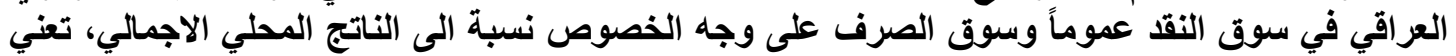

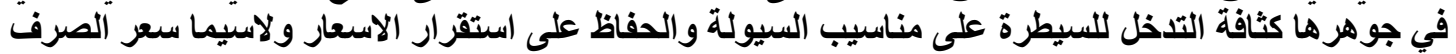

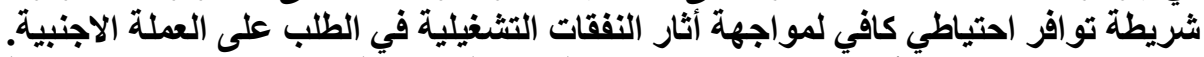

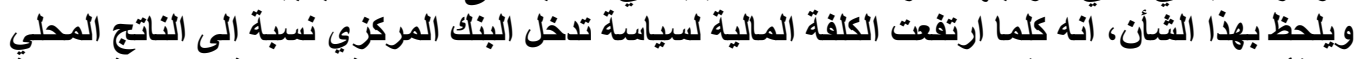

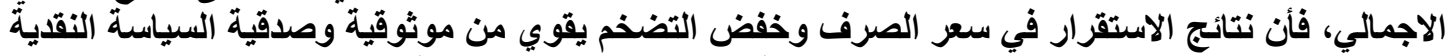

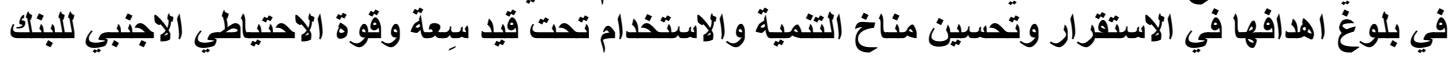
المركزي والعكس بالعكس.

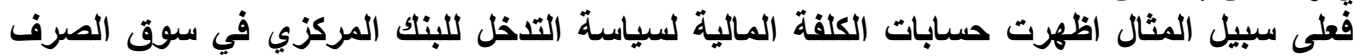

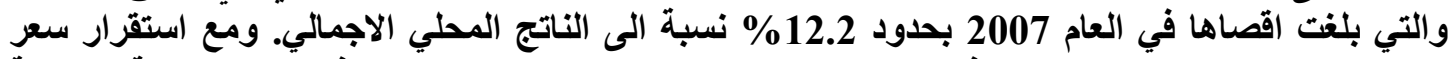

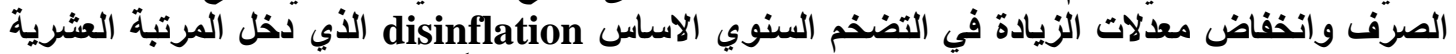

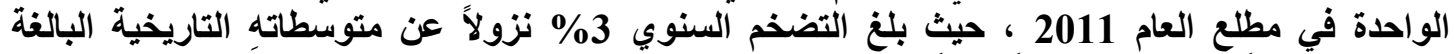

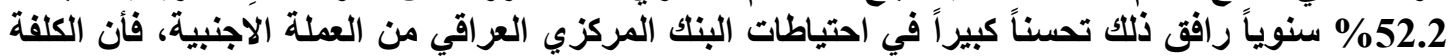

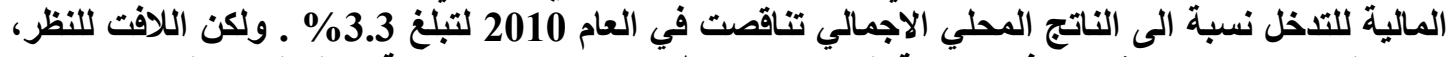

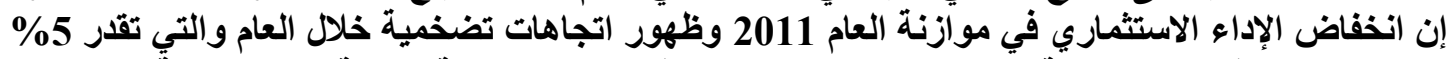

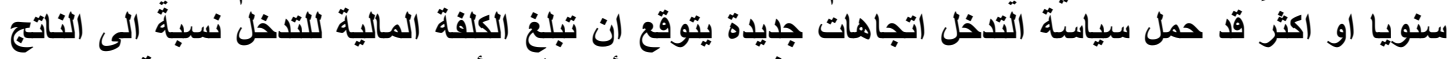

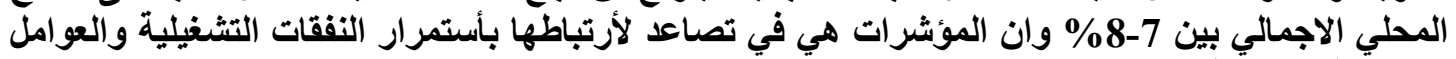




\section{الطاقة الاستيعابية للنفقات النشغيلية}

\section{ومرونة الكلفة المالية للسياسة النقدية}

وعلى هذا الاساس ، فأنه لابد من تحليل نتائج العبء الحقيقي لأنحراف الطاقة الاستيعابية في الموازنة

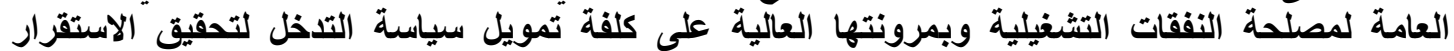

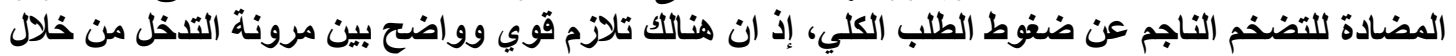

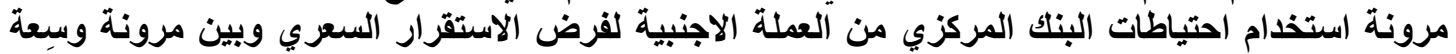

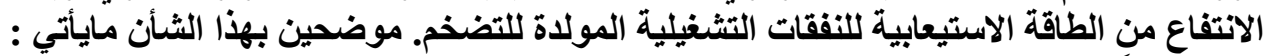

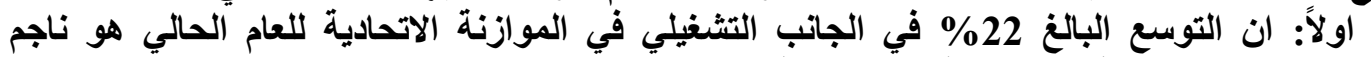

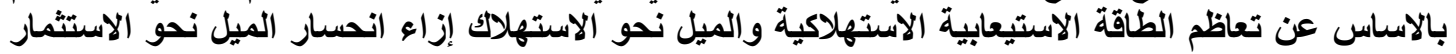

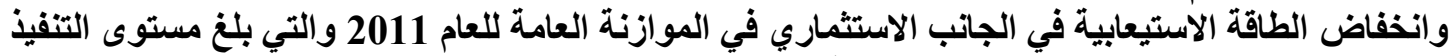

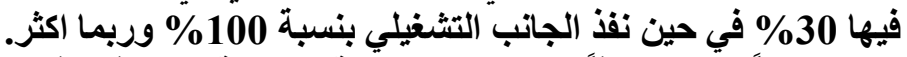

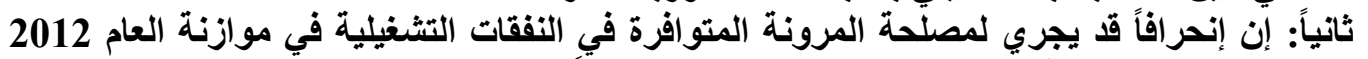

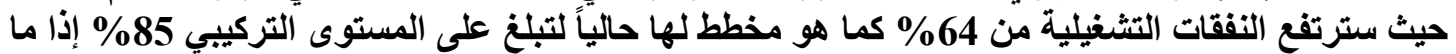

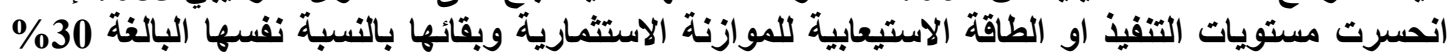

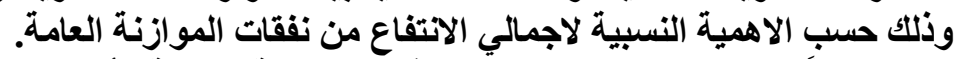

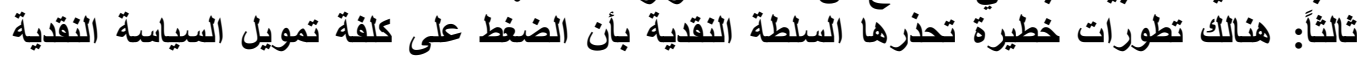

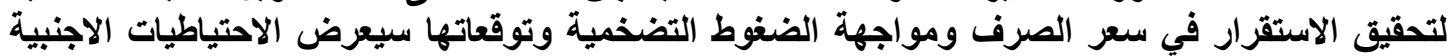

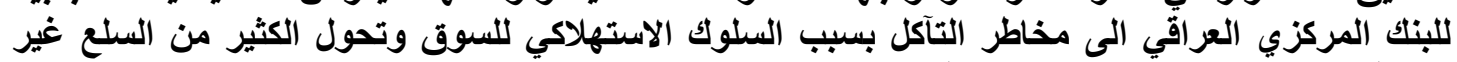

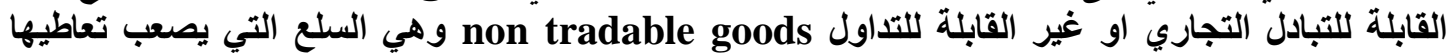

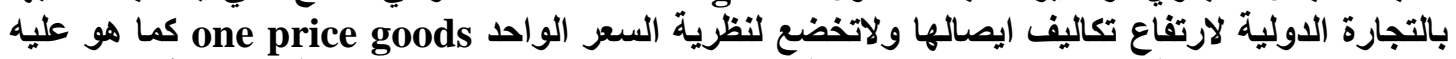

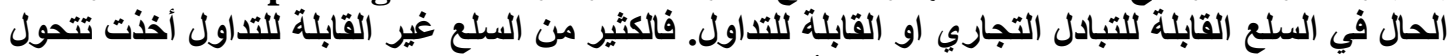

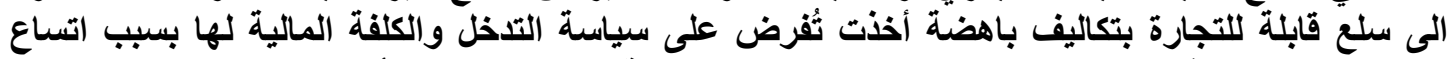

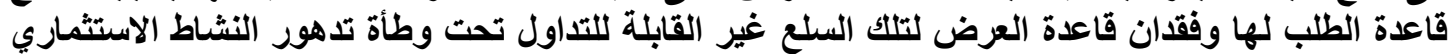

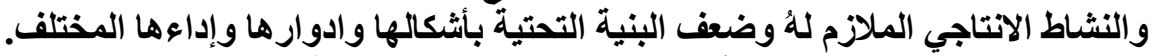

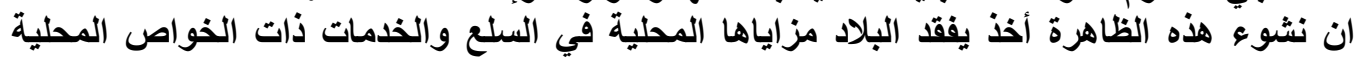

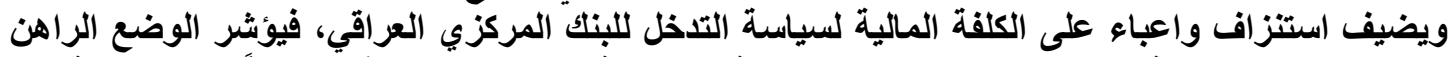

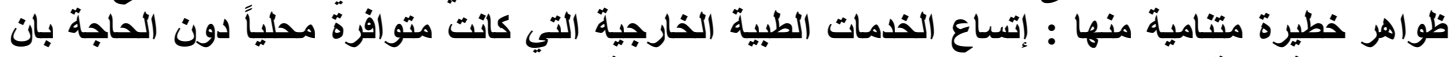

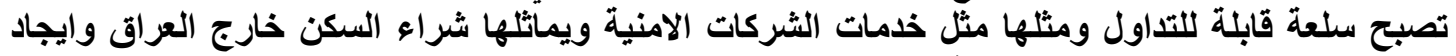

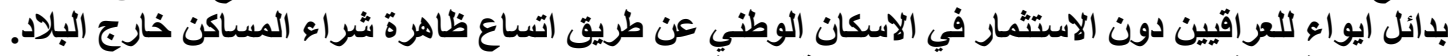

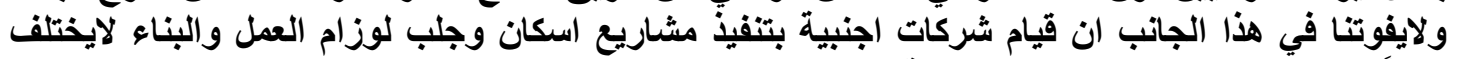

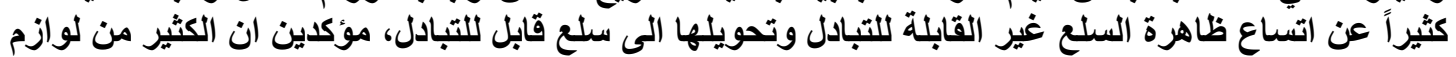

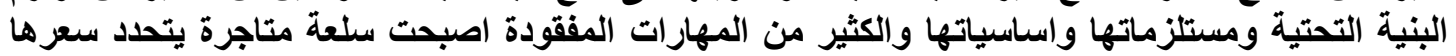

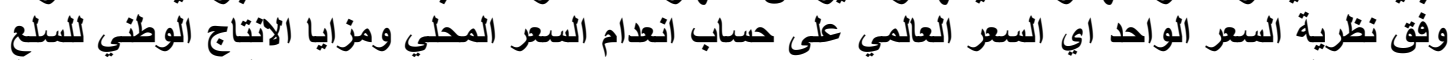

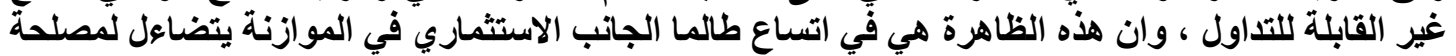




\section{الطاقة الاستيعابية للنفقات التشغيلية}

\section{ومرونة الكلفة المالية للسباسة النقدية}

وخلاصة القول، اصبحت الخدمات الداخلية كسلع غير متداولة اصطلاحاً تحولت الى سلعة قابلة للتبادل

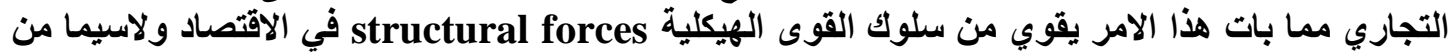

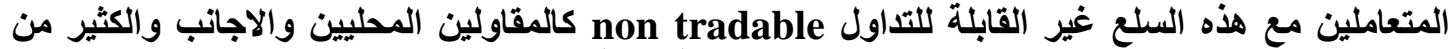

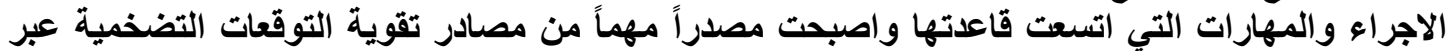

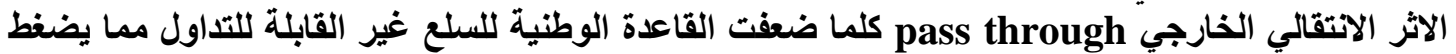

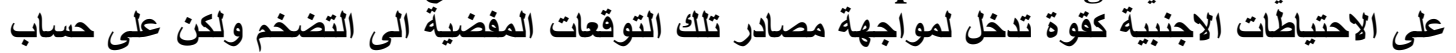

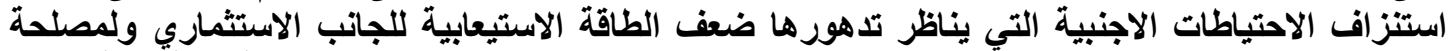

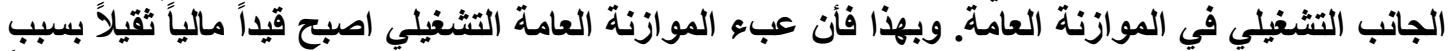

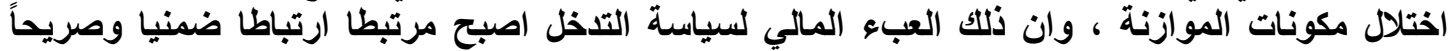

بالموازنة التشغيلية.

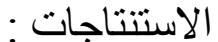

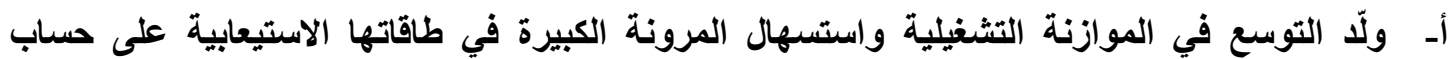

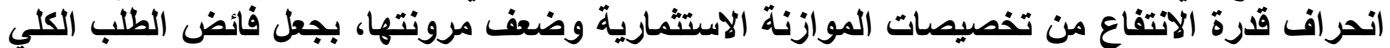

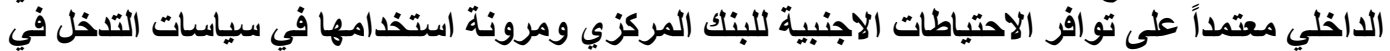

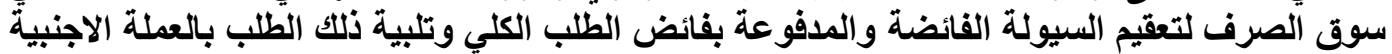

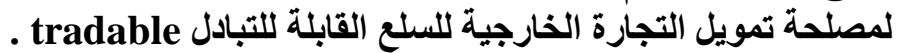

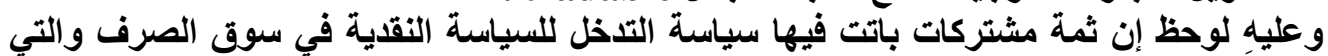

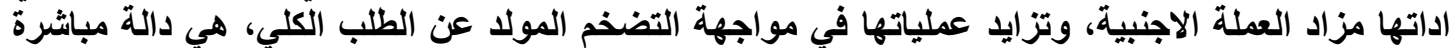

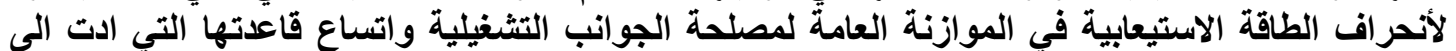

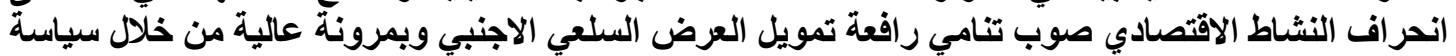

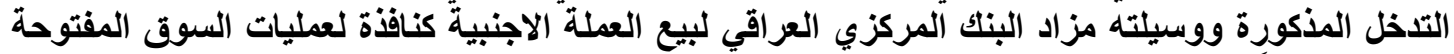

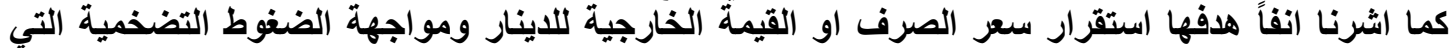
يولاها فائض الطلب الاستهلاكي للموازنة التهائة التثغيلية.

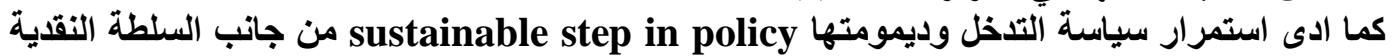

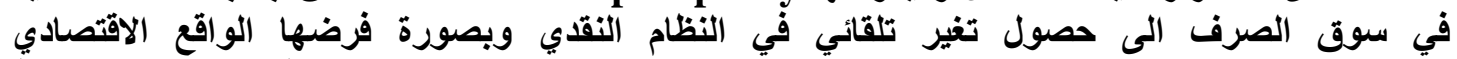
de facto

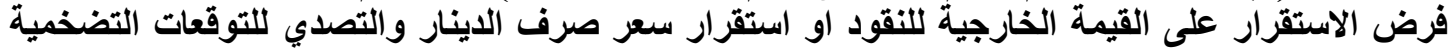

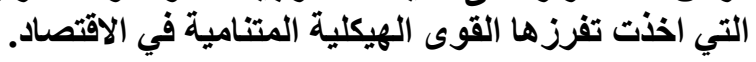




\section{الطاقة الاستيعابية للنفقات التشغيلية}

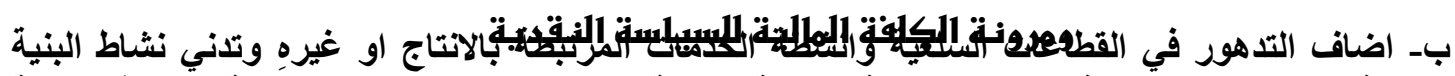

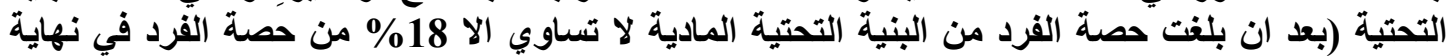

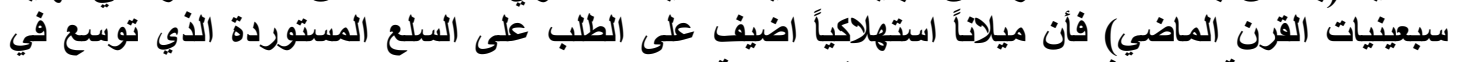

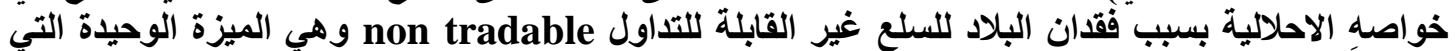

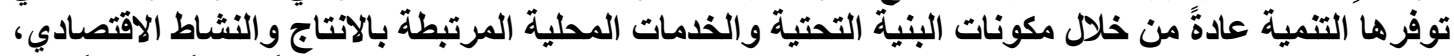

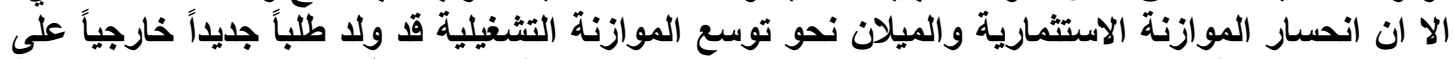

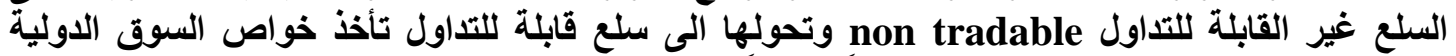

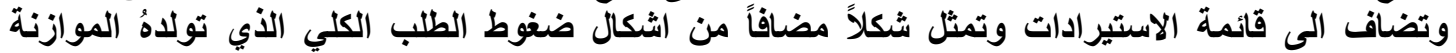

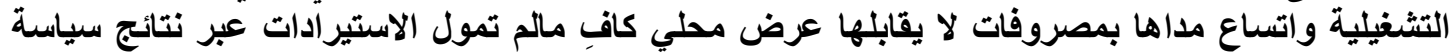

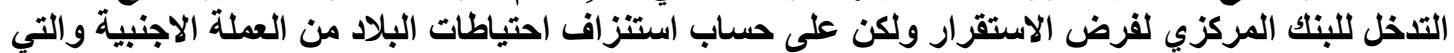

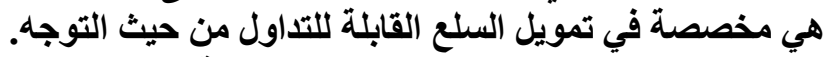

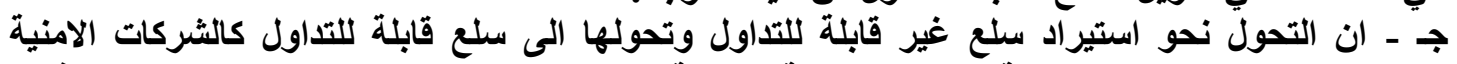

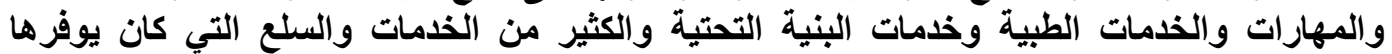

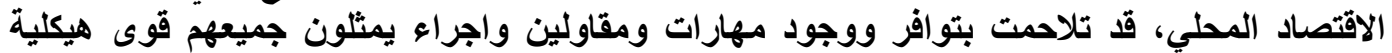

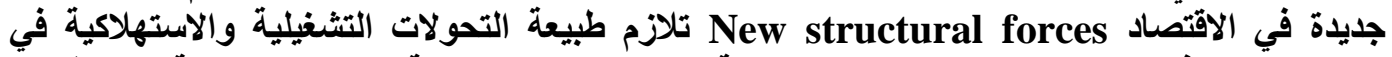

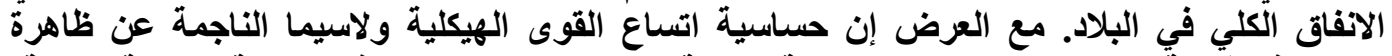

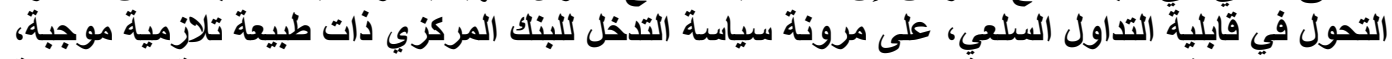

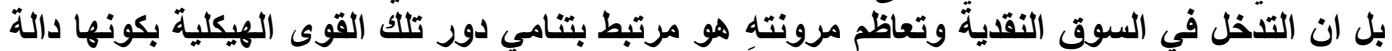

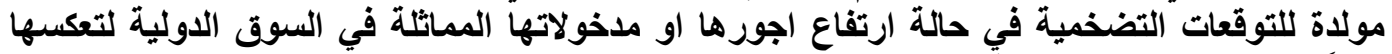

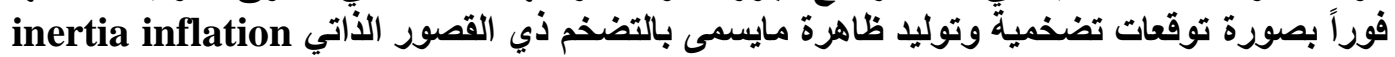

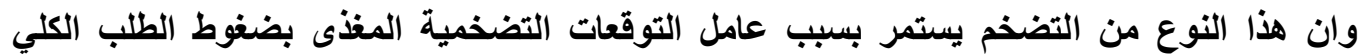

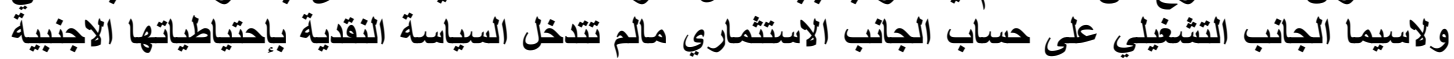

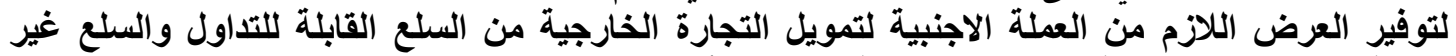

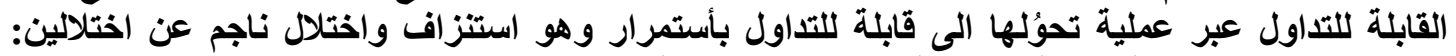

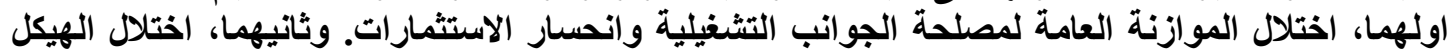

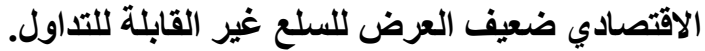

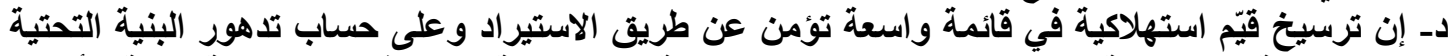

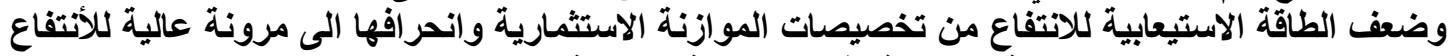

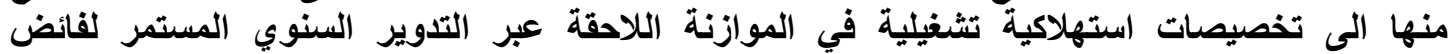

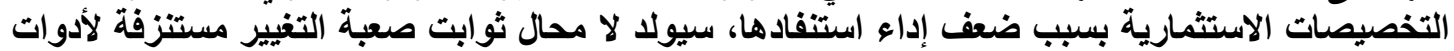

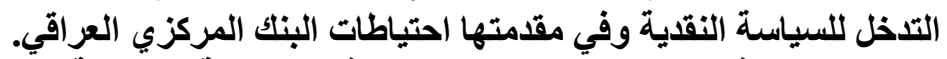

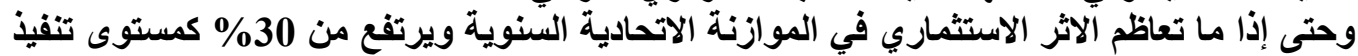

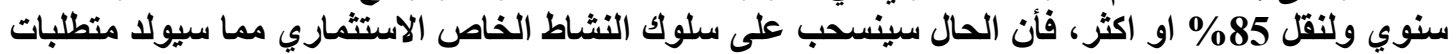

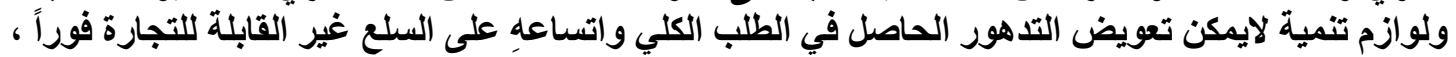

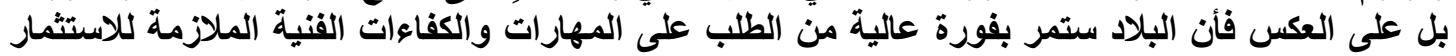

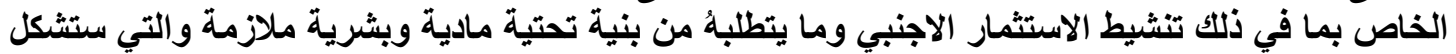

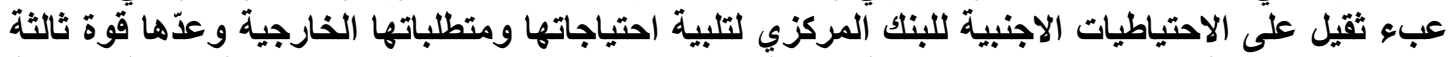

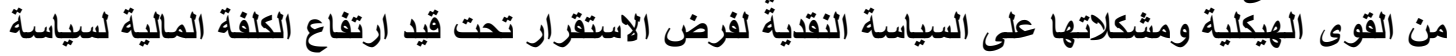




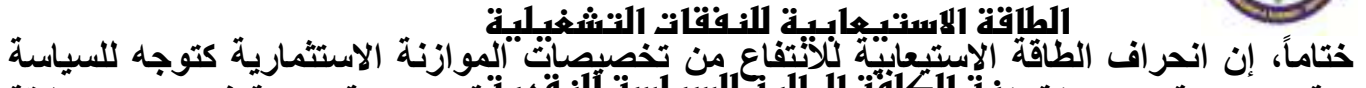

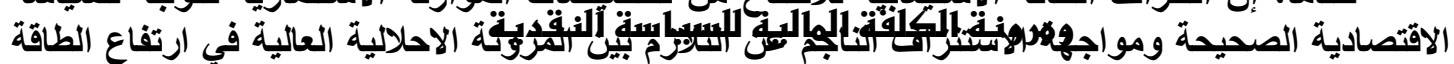

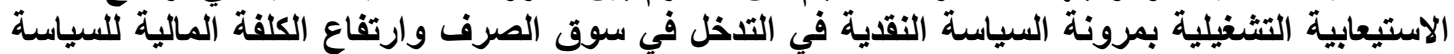

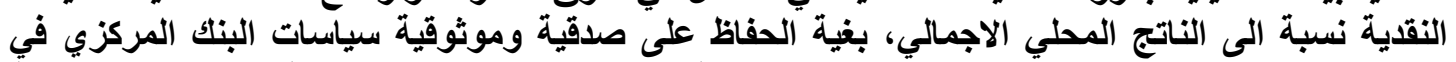

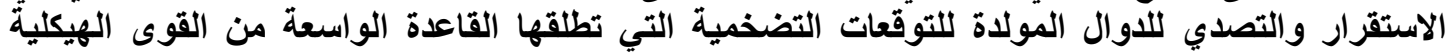
المشار اليها.

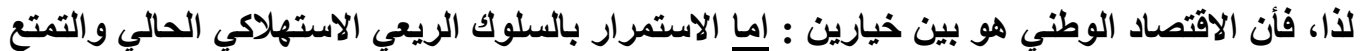

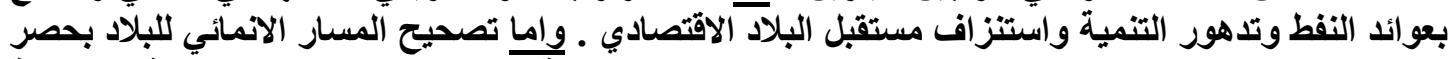

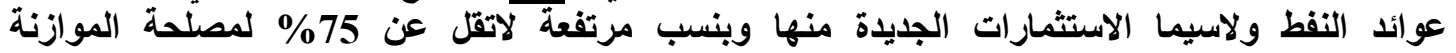

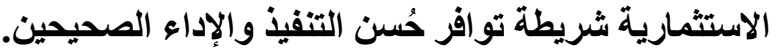

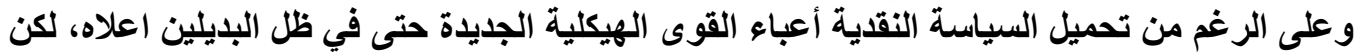

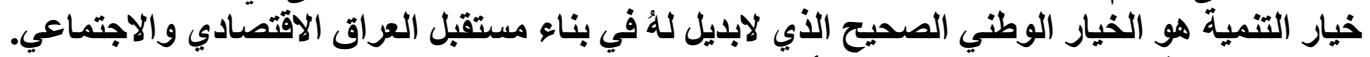

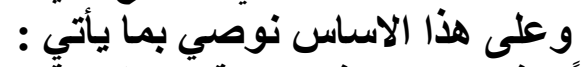

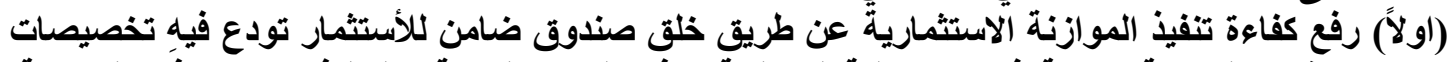

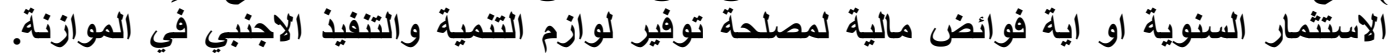

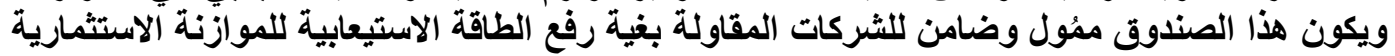

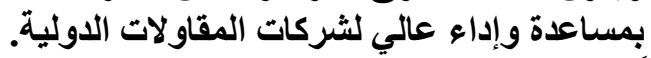

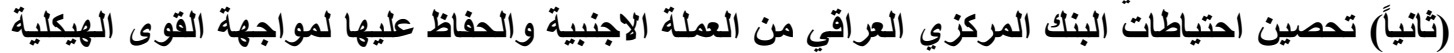

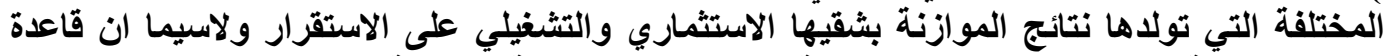

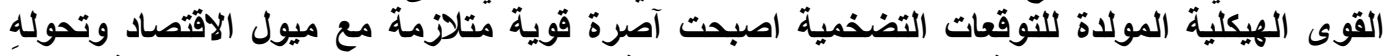

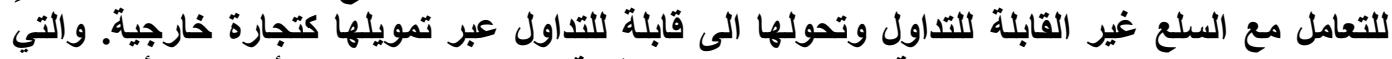

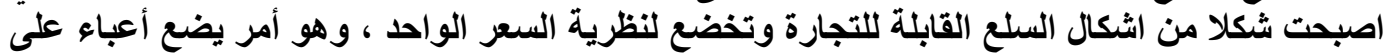

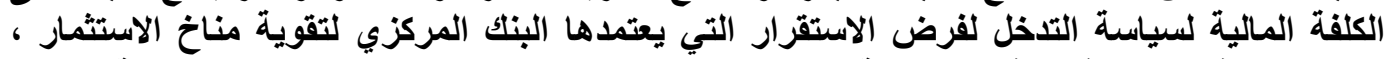

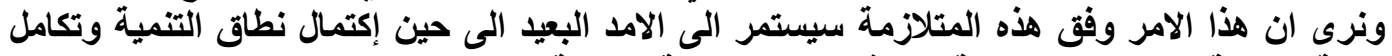

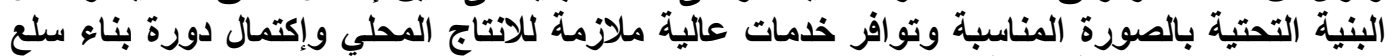

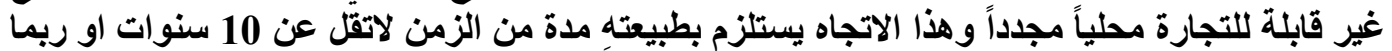


الطاقة الاستيعابية للنفقات النشغيلية

ومرونة الكلفة المالية للسياسة النقدية

هوامش ومصادر البحث

(1)Finn, Mary. G (1995)' Is high capacity Utilization Inflationary? ',

Economic Quarterly. vol.81 issue 1.

(2) حول ما يسمى Balassa- samuelson effect

\section{راجع:}

Burda,M and Wyplosz.C, (2009)"Macroeconomics: A European Text " Ch.15, Oxford University Press

(3)Bamumal ,William .J(1967)"Macro Economics of Unbalanced Growth: the Anatomy of Urban Crises". American Economic Review Vol.57 No.3 , PP 415 426

$$
\text { لاحظ كنلك تفاصيل مهمة في المقالة الاتية الواردة في مجلة (ذي ايكونوميست اللندنية ): }
$$

The service elevator: Can poor countries leapfrog Manufacturing and grow rich on services.? The Economist, May 19 th ,2011

$$
\text { كما اوردت المجلة الاقتصادية نفسها في اعلاه مصادر مهمة تتعلق بثورة الخدمات والتى منها: }
$$

The Service Revolution in South Asia, edited by Ejaz Ghani.

Oxford University Press, 2010.

"Service with a smile: a new growth engine for poor countries" by Ejaz Ghani, Arti Grover and Homi Kharas, VoxEU Wibsite May 4, 2011

"The Service Sector As India's Road To Economic Growth" by Barry

Eichengreen and Poonam Gupta, NBER Working Paper 16757, February, 2011

تطابقت توقعاتنا حقاً مع التوقعات حول معدلات النمو في العام 2012 والواردة في الصفحة 16 من نثرة

Business Monitor Int.

More Economically Viable, But Less Politically Stable

Iraq: Business Forecast Report

Includes 10-year Forecast To 2020

Q3 2011

$$
\begin{aligned}
& \text { مظهزي محمد صالح قاسم / السياسة النقاية للبنك المركزي العراقي : } \\
& \text { مفارقة الازدهار في اقتصاد ريعي العيد } \\
& \text { البنك المركزي العراقي تثرين الثناني } 2011 \text { ـ. }
\end{aligned}
$$

